\title{
COMPRA COMPULSIVA E A INFLUÊNCIA DO CARTÃO DE CRÉDITO
}

\section{RESUMO}

Este artigo investiga a influência do cartão de crédito sobre o comportamento de compra compulsiva entre jovens. A compra compulsiva é um estado de descontrole que visa a minimizar sentimentos negativos. Nesse contexto, o cartão de crédito pode ser um elemento impulsionador de compras que podem ter como possíveis conseqüências a geração de dívidas e problemas de relacionamentos. $\mathrm{O}$ estudo analisou tal comportamento entre jovens universitários, a partir de uma pesquisa de campo. Os resultados sugerem que, na amostra, os jovens com propensão à compulsividade usam o cartão de crédito de forma mais intensa. Sugere-se que as organizações envolvidas não negligenciem a questão da compra compulsiva e que suas responsabilidades sejam discutidas.

\section{Tânia Modesto Veludo-de-Oliveira}

UNIFECAP

\section{Ana Akemi Ikeda}

FEA-USP

\section{Rubens da Costa Santos}

FGV-EAESP

\footnotetext{
ABSTRACT This article examines the influence of credit cards on young adults' compulsive buying behavior. Compulsive buying is an uncontrollable state that tends to soften negative feelings. In this context, credit cards can stimulate impulse buying giving rise to problems such as debts and relationship problems. This study is based on a field work and it analysis this behavior on university students. The results reveal that young students with propensity to be compulsive buyers use credit card intensely. It is suggested that organizations involved in this matter should not neglect the compulsive buying behavior and that a discussion about their responsibility be made.
}

PALAVRAS-ChAVE Compra compulsiva, cartão de crédito, estudantes universitários, comportamento do consumidor, pesquisa de marketing.

KEY WORDS Compulsive buying, credit card, university students, consumer behavior, marketing research. 


\section{INTRODUÇÃO}

O cartão de crédito está se popularizando em diversos segmentos da população, conseqüentemente ocasionando mudanças no comportamento de grupos que não tinham acesso a esse serviço. Percebe-se que, concomitantemente à expansão do cartão de crédito, há um aumento do número de inadimplentes. O descontrole no uso do cartão tem sido apontado como um problema entre jovens que, em retaliação à negligência dos pais, gastam exageradamente (Lejoyeux et al., 1996) ou, por causa da inexperiência, se deixam seduzir com facilidade e acabam acumulando dívidas (Haddad, Patel e Pierre, 2001).

Pessoas que constantemente adquirirem mais do que conseguem pagar podem apresentar indícios de comportamento de compra compulsiva. Verifica-se que esse comportamento se manifesta principalmente entre os jovens (Schlosser et al., 1994; D’Astous, Maltais e Roberge, 1990; O'Guinn e Faber, 1989), sendo que no Brasil o consumo compulsivo parece atingir com mais intensidade indivíduos com idade entre 14 e 25 anos (Prates, 2003).

À medida que atinge prioritariamente o grupo de jovens, esse problema torna-se também alvo de discussão de suas famílias, de educadores e de organizações, tais como empresas de cartões de crédito e órgãos de defesa do consumidor. O ponto focal da discussão é delimitar a responsabilidade de cada um dos agentes.

Assim, é relevante verificar até que ponto essas instituições podem ou devem interferir nos hábitos dos jovens, qual o perfil do jovem que apresenta indícios do comportamento de compra compulsiva, quantos se encontram na condição de compradores compulsivos, como os jovens utilizam o cartão de crédito e o que pode ser feito para gerenciar essa situação.

Este estudo pretende contribuir para o desenvolvimento da compreensão do tema da compra compulsiva no Brasil. Seu objetivo é analisar aspectos do comportamento de compra compulsiva de universitários com o uso do cartão de crédito. De forma específica, procura-se identificar: a pontuação dos jovens classificados como compradores compulsivos; os graus mínimos e máximos de compulsividade de seu comportamento; e os grupos com maior e menor propensão à compulsividade nas compras.

\section{COMPORTAMENTO DE COMPRA COMPULSIVA: DEFINIÇÕES}

Os conceitos relativos ao comportamento de compra compulsiva ainda se apresentam fragmentados. Na li- teratura, verifica-se o emprego de uma quantidade considerável de termos para se referir à compra compulsiva, tais como: compulsive buying, addictive buying, compulsive shopping, compulsive spending e oniomania. Essa diversidade torna ainda mais árdua a tarefa de delimitar o conceito. Como afirmam Hassay e Smith (1996), é necessário desenvolver mais estudos para caracterizá-lo e diferenciá-lo.

De acordo com Ullman e Krasner (1969), um comportamento é considerado compulsivo quando resulta de impulsos compelidos e impelidos, sendo inapropriado ou prejudicial ao indivíduo. O impulso ganha proporções de compulsão quando se torna tão poderoso a ponto de ser irresistível (Rook, 1987). Pode ocorrer com consumidores cujos sentimentos estejam fora de controle (Woodruffe-Burton, Eccles e Elliott, 2002).

A partir de um estudo sobre o processo de formação de impulsos em consumidores, Dholakia (2000) afirma que a existência de regras explícitas atua como uma estratégia de resistência ao impulso, guiando e controlando comportamentos associados ao vício ou ao consumo compulsivo. McElroy, Phillips e Keck (1994b) argumentam que a compra compulsiva é compreendida quase que exclusivamente como um transtorno no controle de impulsos. Para Black (2001, p. 18), ela "apresenta tanto componentes cognitivos como comportamentais - ambos potencialmente causadores de desequilíbrio".

A ocorrência da compra compulsiva foi originalmente notada pela psiquiatria no início dos anos 1900 . Kraepelin (1915) definiu-a como um impulso patológico e Bleuler (1924), como um impulso reativo. Embora os estudos seminais sobre o tema remontem ao início do século XX, foi somente em meados dos anos 1980, segundo Magee (1994, p. 590), que a compra compulsiva começou a receber mais atenção. Em marketing, na área do comportamento do consumidor, os primeiros estudos surgiram por volta da década de 1980, cerca de 60 anos após a abordagem do tema sob a óptica médica (O'Guinn e Faber, 1989; Valence, D'Astous e Fortier, 1988; Faber e O'Guinn, 1988; Moschis e Churchill, 1978).

Segundo Kwak, Zinkhan e Crask (2003, p. 161), atualmente a compra compulsiva é considerada um fenômeno global, sendo tema de pesquisas nos campos da psiquiatria, psicologia e marketing. Faber e O'Guinn $(1989,1992)$ estimam que o comportamento compulsivo ocorre numa faixa entre $1,1 \%$ e $5,9 \%$ da população, enquanto Black (1996) estima que esse número varia entre $2 \%$ e $8 \%$. Ambas as estimativas referem-se aos Estados Unidos. 
McElroy, Phillips e Keck (1994b) definem a compra compulsiva como o comportamento de compra incontrolável e estressante, que consome tempo e resulta em dificuldades financeiras ou sociais. De um modo geral, é possível defini-la como "a tendência a comprar de forma repetitiva e crônica, que se torna uma resposta primária a eventos ou sentimentos negativos" (O'Guinn e Faber, 1989, p. 155). Essa definição é a adotada neste artigo.

É importante observar que a compra compulsiva pode ser confundida ou equivocadamente denominada consumo compulsivo ou compra impulsiva. Embora esses conceitos guardem relações entre si, não possuem o mesmo significado.

Sheth, Mittal e Newman (2001) observam que a compra compulsiva envolve pessoas que estão sempre comprando coisas que talvez nunca usem, em quantidades maiores do que necessitam, mesmo sem ter como pagar por elas. Portanto, a compra compulsiva envolve a tendência de comprar mais do que determinam as necessidades e do que permitem os recursos. Nesse caso, o comprador é altamente envolvido com a atividade de compra em si, estando menos preocupado com o que está adquirindo ou com o que vai consumir.

Diferentemente, o consumo compulsivo se relaciona ao uso de um produto ou serviço de forma descontrolada, sendo que, nesse caso, a fixação é em direção a uma determinada categoria de produtos. Os usuários compulsivos negam as conseqüências prejudiciais do uso do produto e enfrentam repetidos fracassos na tentativa de controlar sua obsessão.

Por sua vez, de acordo com Stern (1962), a compra impulsiva caracteriza-se por ser não-planejada, e é definida por Rook e Fisher (1995, p. 306) como "a tendência do consumidor a comprar espontaneamente, sem reflexão, de forma imediata [...], estimulado pela proximidade física do objeto desejado, dominado pela atração emocional e absorvido pela promessa de gratificação imediata". Conforme Valence, D'Astous e Fortier (1988), ao contrário do que ocorre na compra impulsiva, a compulsão torna a atividade de compra sintomática, acompanhada por um sentimento de restrição e falta de controle, onde a função defensiva aparece claramente. Isso quer dizer que a "compra impulsiva" é um conceito próximo ao da compra compulsiva, mas que não resulta em conseqüências negativas (Rook e Hoch, 1984).

Afinal, o que efetivamente difere a compra compulsiva de conceitos correlatos, como consumo compulsivo ou compra impulsiva? O'Guinn e Faber (1989) concluem que são as motivações e as conseqüências do comportamento, além da freqüência com que ele ocorre.

O comportamento de compra compulsiva se manifesta em diferentes níveis de intensidade, cujo nível máximo são os gastadores viciados. Sobre essa questão, Edwards (1993) sugere que a caracterização do comportamento de compra seja realizada com base em um continuum que se inicia em um nível normal e, gradativamente, atinge o nível de compulsividade. $\mathrm{O}$ modelo proposto, como ilustrado pela Figura 1, refere-se inicialmente ao cliente normal (não compulsivo), passando a níveis mais avançados de compulsividade, até culminar com o comportamento doentio. Após o cliente normal (não compulsivo), o modelo passa à caracterização do cliente que busca lazer e recreação na atividade de compra. Em seguida, passa ao cliente com nível intermediário, cujo comportamento está no limite do compulsivo clássico, chegando, por fim, aos gastadores viciados.

Endossando o modelo, Redden e Steiner (2000) assinalam que a incoerência de pensamento, comportamento e objetivos caracterizam o fanatismo desse perfil de comprador, distinguindo-o daqueles considerados normais ou não-compulsivos. Valence, D'Astous e Fortier (1988), nessa mesma perspectiva, distinguem

Figura 1 - Continuum da compulsividade no comportamento de compra.

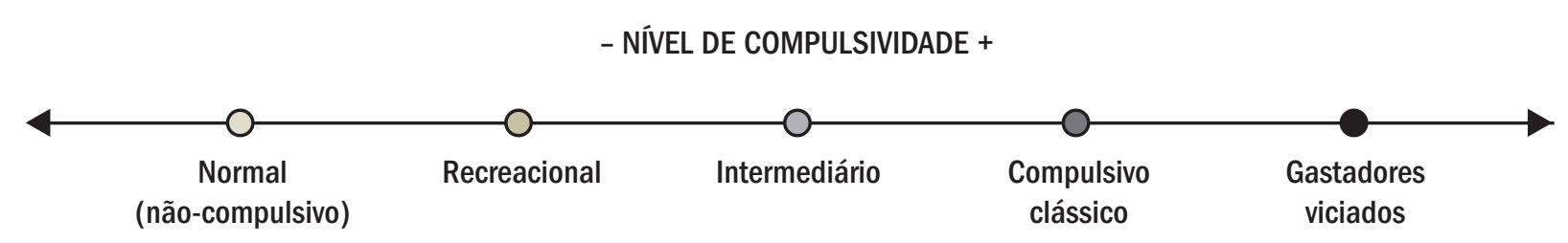

Fonte: Representação proposta pelos autores para ilustrar a classificação de Edwards (1993). 
quatro tipos patológicos de comprador: o reativo e emocional, que atribui certa importância ao simbolismo do produto, e geralmente apresenta motivos emocionais e compensatórios; o impulsivo, que sente um desejo espontâneo e repentino de comprar, e vive em um estado de provável ambivalência psicológica; o fanático, que se interessa somente por um produto (como CDs, livros ou roupas), podendo ter caráter hedonista ou de colecionador; e o descontrolado, que tenta reduzir sua tensão e ansiedade por meio da atividade de compra.

Frost et al. (1998) consideram a compra compulsiva um comportamento obsessivo-compulsivo, que, por sua vez, pode estar associado a outros distúrbios, tais como alcoolismo (Valence, D'Astous e Fortier, 1988; Glatt e Cook, 1987), cleptomania (McElroy et al., 1991), jogo (Schlosser et al., 1994) e transtornos alimentares (Faber et al., 1995). Todavia, conforme explicam Miltenberger et al. (2003), tal comportamento não foi incluído na última edição do DSM - Diagnostic and Statistical Manual of Mental Disorders, de 1994, da American Psychiatric Association. Assim, vale destacar que, segundo Lejoyeux et al. (1996, p. 2), "embora muitos casos de compra descontrolada sejam descritos como transtornos, a maioria dos impulsos de compra é normal", e, por essa razão, a compulsividade nas compras deve ser compreendida em todas as suas graduações.

\section{COMPORTAMENTO DE COMPRA COMPULSIVA: MOTIVAÇÕES E CONSEQÜÊNCIAS}

Faber e Christenson (1996) sugerem que o comportamento de compra compulsiva é usado como uma resposta compensatória a uma frustração ou depressão, na tentativa de se administrar o humor e superar a infelicidade. Eles comentam que os compradores compulsivos demonstram alegria e excitação no momento da compra, procurando substituir um estado de espírito negativo. Adicionalmente, as emoções negativas sentidas anteriormente à compra são mais freqüentes do que as sentidas durante a compra. De acordo com Lejoyeux et al. (1996, p. 5), isso significa que as "emoções negativas, especialmente tristeza, solidão, raiva, frustração e irritação, aumentam a propensão à compra dos compradores descontrolados". Geralmente, a atividade de compra é associada a emoções positivas: ao comprar o indivíduo se sente feliz, poderoso, competente, relaxado ou superior (Rook, 1987).
Contudo, a compra não é capaz de preencher totalmente a sensação de vazio decorrente dos sentimentos negativos, podendo intensificá-los, pois a tensão, temporariamente suavizada pela compra, é rapidamente transferida para um sentimento de culpa (Lejoyeux et al., 1996, Christenson et al., 1994, Valence, D'Astous e Fortier, 1988). Faber e O'Guinn (1988, p. 100) ponderam que "muitos consumidores compulsivos parecem ter pouco prazer com as coisas que compram por temerem que alguém descubra que adquiriram coisas desnecessárias ou que nunca usaram o que foi adquirido".

A função compensatória no comportamento do consumidor foi explorada por Woodruffe (1997), que explicou que certos aspectos do consumo são reações para satisfazer lacunas resultantes de falhas ou fraquezas. De acordo com Woodruffe (1997, p. 325), "provavelmente há uma grande variação nos níveis de lacunas em termos de auto-estima, confiança, paciência, felicidade e outros déficits emocionais", sendo que a resposta dos consumidores pode representar um amplo espectro de comportamentos compensatórios.

A pesquisa de Elliott (1994) confirma que a tendência ao vício do consumo guarda relação com inseguranças, problemas de infância, o fato de a pessoa se sentir desinteressante, depressão e falta de apoio emocional nos relacionamentos. Scherhorn, Reish e Raab (1990) enfatizam os baixos níveis de auto-estima e os altos níveis de depressão nesse tipo de comprador. Corroborando essa visão, o trabalho de Edwards (1993) mostrou que o comprador compulsivo apresenta um nível mais elevado de ansiedade em relação ao não compulsivo, e que ele realiza compras principalmente em períodos de estresse. Nataraajan e Goff (1991) explicam que esse pode ser um meio de pessoas tímidas ou preocupadas com a família extravasarem sua agressividade. Faber e Christenson (1996) apontam o desejo por estimulação, a alta propensão a fantasiar e o desejo de ser reconhecido como características desses compradores, que podem ser influenciados por aspectos psicológicos, sociológicos e bioquímicos.

Para Roberts (1998), os fatores que contribuem para a ocorrência da compra compulsiva podem ser agrupados em três segmentos. O primeiro refere-se às influências psicológicas, incluindo auto-estima, percepção do status social e fantasias. O segundo fator relaciona-se às influências familiares. A compra compulsiva é comum em famílias que já possuem esse transtorno (Valence, D'Astous e Fortier, 1988). Com base nisso, D'Astous, Maltais e Roberge (1990) não descar- 
tam a herança genética como uma alternativa plausível para explicá-la, sendo que Hirschman e Stern (2001) descobriram um gene - D2DR - presente de modo desproporcional em pessoas com esse perfil.

Ainda sobre as influências familiares, Rindfleisch, Burroughs e Denton (1997) examinaram os impactos da estrutura familiar no comportamento de compra compulsiva de jovens adultos, concluindo que aqueles originados de famílias divorciadas obtêm pontuações significantemente superiores nas medidas de compulsividade. Por outro lado, Roberts, Manolis e Tanner Jr (2003), retomando aspectos da mesma pesquisa e aplicando-a em estudantes colegiais, não encontraram relação direta entre a estrutura familiar e a compulsividade nas compras. Talvez uma das causas da diferença nos resultados seja a faixa etária das amostras, pois enquanto a primeira pesquisa compreendeu jovens adultos, a segunda compreendeu adolescentes.

Por fim, o terceiro segmento citado por Roberts (1998) diz respeito às influências sociológicas, envolvendo a pressão dos pares, a televisão, a freqüência de compra, bem como o uso e a acessibilidade do cartão de crédito. Como afirma Lejoyeux et al. (1996, p. 2), "cartões de crédito, caixas automáticos, crédito instantâneo, sistemas de entrega em domicílio e a propaganda facilitam e incitam a compra de itens por impulso". Adicionalmente, são considerados por Valence, D'Astous e Fortier (1988) a cultura, e o ambiente comercial, além da propaganda, como fatores socioculturais que contribuem para a compra compulsiva. Vale destacar que "o grupo compulsivo reage mais favoravelmente a propagandas orientadas à imagem do que outros grupos" (D'Astous, Maltais e Roberge, 1990, p. 306).

Block, Ridgeway e Dawson (1994) analisaram os impactos do shopping center no comportamento do consumidor e notaram que algumas influências negativas estão presentes. O shopping center reforça valores materialistas por concentrar, em um só local, a apresentação de muitos produtos associados à "boa vida". Nos relatos apresentados por Rook (1987), alguns consumidores contam que sentem os produtos chamarem por eles, pedindo que sejam comprados. Por isso, existe a possibilidade de o indivíduo com tendência à compra compulsiva manifestar seu comportamento no ambiente do shopping center, assim como agiria um jogador compulsivo em um cassino (Block, Ridgeway e Dawson, 1994). Ademais, O'Guinn e Faber (1989) acreditam que a manutenção da auto-estima, obtida por meio da interação com os vendedores, é um aspecto importante para a função compensatória da compra compulsiva. Nesse ponto, as opiniões de McElroy, Phillips e Keck (1994b) são convergentes. Para esses autores, esse tipo de compra é vista como uma tentativa de neutralizar a ansiedade e a experiência de desconforto por meio de contato com o vendedor.

O gênero é apontado como um preditor do comportamento de compra compulsiva, sendo as mulheres as principais vítimas. Tal constatação está em consonância com os trabalhos de D'Astous, Maltais e Roberge (1990), Faber e O'Guinn (1992), McElroy et al. (1994a), Black (1996), Woodruffe (1997), Hirschman e Stern (2001) e Woodruffe-Burton, Eccles e Elliott (2002). O estudo de Miltenberger et al. (2003) também ratifica tais considerações. Ao investigar um grupo de mulheres, os pesquisadores descobriram que as emoções negativas são os antecedentes mais comuns da compra compulsiva, ao passo que a euforia e o alívio são as conseqüências imediatas.

Para finalizar a discussão sobre as motivações que levam à compra compulsiva, devem-se ressaltar os argumentos de Desarbo e Edwards (1996). Esses autores sustentam que depressão, ansiedade, frustração e baixa auto-estima afetam o comprador compulsivo e seus relacionamentos pessoais, sendo que esses estados mentais podem ser avaliados tanto como motivações quanto como conseqüências de tal comportamento.

Conforme lembram Black (1996), Elliott, Eccles e Gournay (1996), Boedecker, Morgan e Stoltman (1999), e Roberts e Jones (2001), o endividamento, as falências pessoais, os problemas legais, o estresse, as dívidas no cartão de crédito e os problemas de convivência se destacam como conseqüências freqüentes. Christenson et al. (1994) apresentam alguns números a esse respeito: o transtorno acaba levando a grandes débitos $(58,3 \%)$, dificuldades no pagamento de dívidas $(41,7 \%)$, conseqüências financeiras e legais $(8,3 \%)$ e problemas criminais $(8,3 \%)$.

\section{O USO dO CARTÃO DE CRÉDITO ENTRE JOVENS}

Algumas pesquisas enfatizam as relações entre o comprador compulsivo e o uso do cartão de crédito. Faber e O'Guinn (1988), por exemplo, acreditam que algumas pessoas com problemas de crédito possuem padrões de compra similares aos do comportamento compulsivo. Os autores comentam que, quando os respondentes de sua pesquisa se referiam ao uso do cartão de crédito, naturalmente o associavam a sentimentos de poder e importância $(13,6 \%)$, e a gastar mais do que 
podiam pagar (27,3\%). Roberts (1998) acredita que, comparativamente ao dinheiro, o cartão de crédito estimula mais os gastos pelo seguinte motivo: o valor envolvido na transação com cartão pode ser encarado como algo irreal ou abstrato; ou seja, intangível para o indivíduo. Também é provável que o comprador compulsivo tenha mais cartões que os demais compradores (Black, 2001; Christenson et al. 1994; O'Guinn e Faber, 1989). Por sua vez, D'Astous (1990, p. 25) afirma que "o fato de o cartão de crédito eliminar ou atenuar a necessidade de se ter dinheiro para comprar algo pode levar a uma aceleração no desenvolvimento do vício do consumo".

Em relação aos estudantes universitários, a acumulação de dívidas no cartão de crédito está se tornado uma questão preocupante. Os cartões são fáceis de obter, e os jovens estão adquirindo e usando cada vez mais esse serviço (Learning..., 2003). Enfatizando o segmento de jovens, Warwick e Mansfield (2000) conduziram uma investigação com 381 graduandos e pósgraduandos. O objetivo do estudo era verificar seus conhecimentos em relação ao uso do cartão de crédito. A maioria dos entrevistados mostrou ignorar as taxas de juros cobradas nesse serviço e aproximadamente a metade da amostra desconhecia o limite de crédito.

A relação entre o comportamento de compra compulsiva em jovens e o uso do cartão de crédito foi evidenciada em um estudo conduzido por Roberts e Jones (2001). Em um modelo, os pesquisadores procuraram estabelecer a relação entre a compra compulsiva, as atitudes do comprador em relação ao dinheiro e o uso do cartão de crédito. Eles analisaram o comportamento de universitários e chegaram à conclusão de que o cartão de crédito atua como elemento moderador entre as atitudes do comprador e a compra compulsiva.

No estudo de Roberts e Jones, três construtos foram analisados: "poder e prestígio", "desconfiança" e "ansiedade". Os construtos "poder e prestígio" e "ansiedade" estão diretamente relacionados à compra compulsiva. Jovens com necessidade de se auto-afirmar e mostrar prestígio usam o dinheiro para influenciar e impressionar os outros. Para eles, o dinheiro é sinônimo de status e poder, e uma ferramenta para obter respeito em seus grupos de convivência. Essa abordagem vai ao encontro do trabalho de La Barbera (1988), que estudou o consumo como forma de obter visibilidade e evidência. Para alguns indivíduos, o ato de compra é obviamente um símbolo de status, resultante de sua "habilidade" de comprar em lojas sofisticadas.

Retomando o trabalho de Roberts e Jones (2001), a "desconfiança" é uma atitude inversamente relacionada à compra compulsiva, pois quanto maior a sensibilidade a preços do consumidor menores são as chances de ele adquirir produtos de forma repetitiva e exagerada. Além disso, esses autores avaliaram diferenças de comportamento segundo a intensidade de uso do cartão de crédito. No grupo de estudantes que fazem uso intenso dele, o estudo indicou uma forte associação entre "poder e prestígio" e compra compulsiva. Analogamente, na mesma categoria de estudantes, encontrou-se uma forte associação entre a dimensão "ansiedade" e a compra compulsiva. Em contrapartida, o estudo mostrou que essas atitudes não interferem no comportamento de estudantes que fazem uso restrito do cartão de crédito, ou cujo uso se encontra dentro da média.

\section{METODOLOGIA}

A pesquisa de campo foi realizada em 2002 e 2003 Por questão de conveniência foram coletadas informações de uma amostra não probabilística composta por 248 estudantes na cidade de São Paulo. Os questionários foram aplicados em salas de aula de cursos de Administração de diferentes faculdades, sendo que, das 248 entrevistas realizadas, 188 questionários completos constituíram a amostra deste estudo e foram considerados para análise. As respostas dos que não possuíam cartões de crédito foram desconsideradas.

O questionário dividia-se em duas partes. A primeira parte baseou-se na escala de Faber e O'Guinn (1992), também conhecida por diagnostic screener for compulsive buying (DSCB). Segundo Black (2001, p.20), o DSCB é considerado uma importante ferramenta para a identificação e o diagnóstico da compra compulsiva, e desde sua elaboração é utilizado em diferentes investigações (e.g. Miltenberger et al., 2003, Kwak, Zinkhan e Crask, 2003; Roberts e Jones, 2001; Roberts e Sepulveda, 1999; Lyi, Lee e Kwak, 1997ab; Rindfleisch, Burroughs e Denton, 1997; Faber e Christenson, 1996; Faber et al., 1995; Rook e Fisher, 1995).

A segunda parte do questionário buscava analisar o uso do cartão de crédito, baseando-se na escala de Roberts e Jones (2001). Essa escala é composta por um conjunto de questões que relacionam a compra compulsiva à intensidade do uso do cartão de crédito. Foram incluídas na escala de Roberts e Jones (2001) duas questões sobre a dívida no cartão. Uma delas é específica sobre o parcelamento. Foi introduzida por 
ser essa uma prática bastante disseminada no Brasil.

Considerando o nível de compulsividade obtido pelos entrevistados na escala de Faber e O'Guinn (1992), dividiu-se a amostra em quatro partes (quartis), cada uma contendo 47 respondentes com pontuações semelhantes. Dos 188 questionários, analisaram-se com mais detalhes as respostas dos 47 jovens incluídos no quartil com pontuação mais próxima do limite da compulsividade. Nesse grupo, 15 jovens foram identificados como compradores compulsivos, por obterem pontuações mais baixas que $-1,34$ na escala. As considerações dos respondentes sobre o uso do cartão de crédito foram analisadas de forma comparativa. Os resultados da pesquisa de campo foram analisados e comparados às análises provenientes dos levantamentos bibliográficos e documentais, fornecendo subsídios para a discussão e as conclusões.

\section{RESULTADOS E ANÁLISE}

Os Gráficos 1 e 2 ilustram a distribuição do comportamento de compra compulsiva na amostra e a intensidade do uso do cartão de crédito dos estudantes universitários pesquisados.

O Gráfico 1 mostra uma concentração de respondentes ao lado direito da curva normal, indicando que o comportamento dos estudantes possui uma orientação predominantemente não-compulsiva. A mediana encontrada foi 1,54 , sendo o valor -7,03 correspondente ao comportamento extremo da compra compul- siva, e o valor 3,61 correspondente ao que mais se afasta da compulsividade. Isso significa que a pontuação de 1,54 divide a amostra em duas partes iguais e que 94 respondentes encontram-se na faixa de 0,62 a 2,37. Os jovens com menos propensão à compulsividade estão no quartil 2,37 (faixa de 2,37 a 3,61), que soma 47 estudantes.

Três estudantes obtiveram a pontuação de 3,61, que é o menor grau de compulsividade da escala. Os universitários que se encontram no quartil 0,62 (faixa de 0,62 a -7,03) apresentam os maiores indícios de compulsão nas compras, somando 47 indivíduos. Nesse quartil estão os jovens classificados como compulsivos, que obtiveram pontuações inferiores a $-1,34$. $\mathrm{O}$ comportamento compulsivo foi identificado em 15 estudantes com as seguintes pontuações: $-3,52,-2,72$, $-2,69,-1,97,-1,95,-1,93,-1,67,-1,59,-1,56$ (pontuação de três estudantes), -1,55, -1,39, -1,38, -1,35.

A escala de Roberts e Jones (2001) é baseada na escala Likert, onde " 1 " representa o nível mais intenso no uso do cartão de crédito e " 5 " representa a menor intensidade. Em sua investigação, os autores utilizaram a média para avaliar os resultados obtidos (apesar de se tratar de uma escala ordinal), encontrando o valor de 2,40. Na presente investigação, encontrou-se média de 4,08, o que significa que, em comparação com a amostra de estudantes norte-americanos, os estudantes brasileiros demonstraram um comportamento menos orientado ao uso intenso e desregulado do cartão de crédito. É relevante assinalar as diferenças entre Brasil e Estados Unidos em relação ao padrão e com-

\section{Gráfico 1 - 0 comportamento de compra compulsiva em estudantes universitários.}

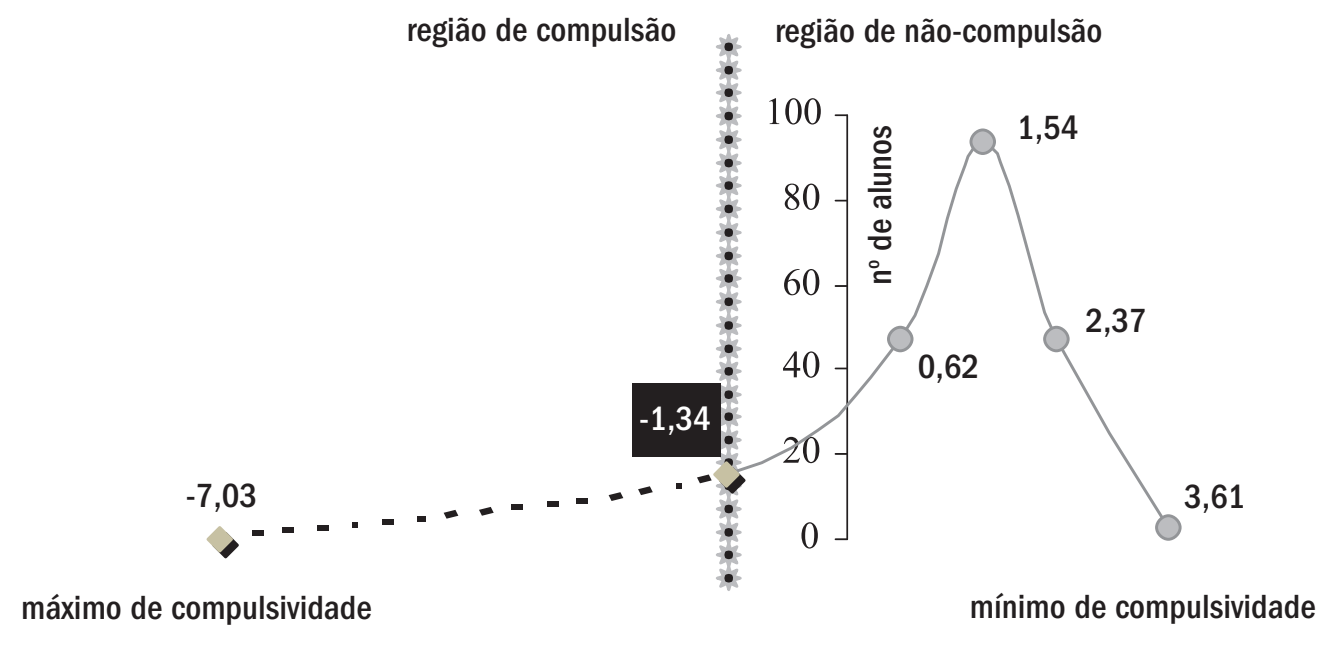


portamento de consumo, e disseminação do uso de cartão de crédito.

O Gráfico 2 mostra os resultados da pesquisa e indica uma predominância de alunos que usam o cartão de crédito de modo responsável e restrito. Do total de 188 respondentes, 12 obtiveram pontuação 5,00, que revela a intensidade mínima no uso desse serviço. Tais participantes praticamente não são afetados pelas facilidades que o instrumento proporciona para a realização de compras. Nenhum entrevistado atingiu a pontuação 1,00, referente à máxima intensidade no uso do cartão; a pontuação que corresponde ao uso mais intenso da amostra é 2,50, obtida por dois jovens classificados como compradores compulsivos. A mediana encontrada foi 4,16 , que divide a amostra em duas partes iguais, sendo o quartil 3,66 (faixa de 3,66 a 1,00) aquele do grupo que usa o cartão de crédito de forma mais intensa.

Alguns paralelos entre os resultados apresentados nos Gráficos 1 e 2 merecem destaque. Dos 47 estudantes que estão no quartil 0,62 do Gráfico 1 (escala de Faber e O'Guinn, 1992), 25 também estão no quartil 3,66 do Gráfico 2 (escala de Roberts e Jones, 2001). Isso quer dizer que 25 dos 47 jovens mais propensos à compra compulsiva pertencem ao grupo que usa o cartão de crédito de forma mais intensa. Essa observação reforça a proposta de alguns pesquisadores (e.g. Roberts e Jones, 2001; Black, 2001; Roberts, 1998; Christenson et al., 1994; D'Astous, 1990; O'Guinn e Faber, 1989; Faber e O'Guinn, 1988), que relacionam a compra compulsiva e o uso intenso do cartão de crédito.

Analogamente, observou-se que 11 dos 15 compra- dores compulsivos usam o cartão de crédito de forma intensa, pois estão no quartil 3,66 do Gráfico 2, sendo que um dos estudantes compulsivos declarou possuir 4 cartões e outro, 3 cartões.

Sobre as questões adicionadas ao questionário, dos 47 jovens que apresentam comportamentos mais orientados à compra compulsiva, 18 declararam sempre parcelar suas compras no cartão e 25 indicaram que o cartão de crédito é o principal meio para realização de compras. Entre os compradores compulsivos, 4 sempre parcelam as compras no cartão e 11 o usam como principal meio de pagamento (ver Tabela 1).

\section{CONSIDERAÇÕES FINAIS}

A influência da compra compulsiva no comportamento de jovens não pode ser negligenciada. Estudos como os indicados por O'Guinn e Faber (1989), D'Astous, Maltais e Roberge (1990) e Schlosser et al. (1994) mostram que esse grupo é o mais propenso a desenvolver o descontrole nos gastos. Indivíduos com esse perfil correm o risco de levar o mau hábito iniciado na juventude para o resto da vida.

O cartão de crédito, conforme concluem Roberts e Jones (2001), atua como elemento mediador entre a compra compulsiva e as atitudes do comprador. A pesquisa de campo realizada no âmbito deste estudo reforça o argumento desses autores, pois é possível observar que os jovens com pontuações mais próximas à compulsividade são, em sua maioria, os mesmos que declararam usar o cartão de forma mais intensa, pre-

\section{Gráfico 2 - A intensidade no uso do cartão de crédito por estudantes universitários.}

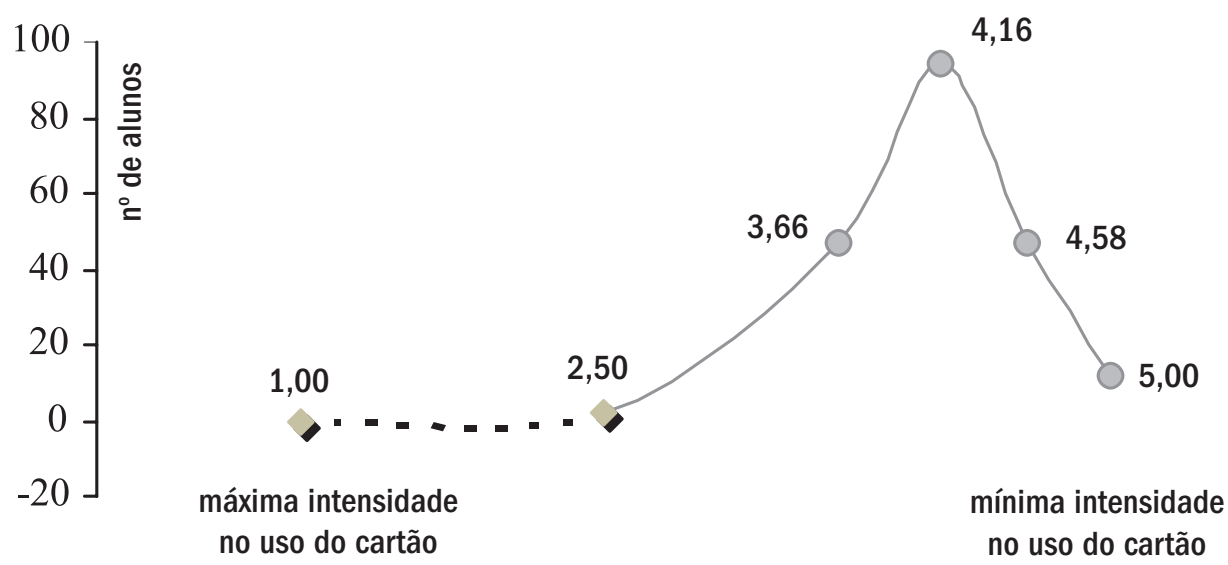


ferindo, em muitos casos, o uso do cartão a outras formas de pagamento. Na pesquisa de campo chamou a atenção o fato de os compradores compulsivos possuírem mais cartões que os não compulsivos, como também constataram O'Guinn e Faber (1989), Christenson et al. (1994) e Black (2001).

É possível que os jovens com o perfil de comprador compulsivo comprem sem levar em conta a utilidade das aquisições ou seus limites de orçamento. Possivelmente agem desse modo para tentar se sentir melhor e reduzir o nível de ansiedade, como o assinalam O'Guinn e Faber (1989), Edwards (1993), Faber e Christenson (1996), Lejoyeux et al. (1996) e Woodruffe (1997). Talvez esses jovens tenham encontrado nas atividades de compra combinadas com o uso do cartão de crédito um caminho para mascarar suas dificuldades.

As organizações relacionadas a essa questão, como as empresas administradoras de cartões de crédito, os estabelecimentos de comércio, os bancos e outras organizações de proteção e defesa do consumidor, bem como os educadores, as famílias e os próprios usuários, devem discutir as responsabilidades de todos os envolvidos. De fato, os elos dessa cadeia possuem papéis relevantes e específicos na orientação e educação dos participantes, sejam eles intermediários ou usuários finais.

Os resultados obtidos nesta pesquisa, de caráter exploratório, levam a algumas recomendações no sentido de estimular a reflexão sobre o assunto. Cada um dos agentes e instituições deve atentar às atividades de comunicação, visando à conscientização dos usuários quanto ao uso responsável do cartão de crédito, mostrando as vantagens que ele proporciona e alertando sobre os riscos e situações pesquisadas neste estudo. Esses agentes podem também promover programas educacionais, políticas de controle e acompanhamento de gastos ocorridos e, adicionalmente, assistir e orientar aqueles usuários que apresentem sintomas típicos da compra compulsiva.

Essas instituições, juntamente com a comunidade que defende os interesses do consumidor, poderão disseminar informações sobre as conseqüências decorrentes do uso indevido ou descontrolado do cartão, assim como sobre a utilização correta desse serviço. As organizações que defendem os interesses do consumidor poderão estimular as empresas do ramo na busca de alternativas que minimizem o problema, como o cartão prépago, em que o comprador somente pode gastar o que está previamente estipulado como limite de crédito.

O estudo sobre a compra compulsiva no Brasil é recente e ainda pouco desenvolvido. Vale lembrar que os resultados obtidos na pesquisa empírica não podem ser generalizados, porém servem de base para o desenvolvimento de mais estudos sobre o tema. Para pesquisas futuras, sugere-se a elaboração de investigações com foco na postura que as instituições atuantes nesse setor estão assumindo frente ao tema da compulsividade: estariam preocupadas ou conscientes da gravidade da questão? Além disso, seria interessante buscar um maior entendimento da influência que os fatores culturais exercem sobre o comprador compulsivo no Brasil, envolvendo a elaboração de instrumentos de pesquisa adaptados à realidade brasileira. Por fim, recomenda-se realizar pesquisas baseadas em amostragem probabilística, que permitirão expandir as contribuições iniciais feitas neste estudo.

Tabela 1 - Paralelo entre os comportamentos de compra de estudantes universitários em relação à compulsividade.

\begin{tabular}{|c|c|c|c|}
\hline VARIÁVEIS & $\begin{array}{l}\text { ORIENTAÇÃO À COMPRA } \\
\text { COMPULSIVA (3 QUARTIS) }\end{array}$ & $\begin{array}{l}\text { ORIENTAÇÃO À COMPRA } \\
\text { COMPULSIVA (1 QUARTIL) }\end{array}$ & $\begin{array}{l}\text { COMPRADORES } \\
\text { COMPULSIVOS }(*)\end{array}$ \\
\hline Amostra & $\begin{array}{c}141 \\
(75,0 \% \text { do total } \\
\text { de } 188 \text { jovens })\end{array}$ & $\begin{array}{c}47 \\
(25,0 \% \text { do total } \\
\text { de } 188 \text { jovens })\end{array}$ & $\begin{array}{c}15 \\
\text { (7,9\% do total } \\
\text { de } 188 \text { jovens })\end{array}$ \\
\hline Gênero feminino & 65 & 28 & 8 \\
\hline Gênero masculino & 76 & 19 & 7 \\
\hline Média de idade (anos) & 24,54 & 22,87 & 23,33 \\
\hline Média de cartões de crédito por pessoa & 1,31 & 1,51 & 1,86 \\
\hline Pagam suas próprias despesas no cartão & 93 & 38 & 13 \\
\hline Dividem com os pais as despesas no cartão & 32 & 5 & 1 \\
\hline Pais pagam por suas despesas no cartão & 16 & 4 & 1 \\
\hline Jovens que usam o cartão de forma intensa & 20 & 25 & 11 \\
\hline
\end{tabular}

* Subamostra da coluna anterior 


\section{REFERÊNCIAS BIBLIOGRÁFICAS}

BLACK, D. Compulsive buying: a review. Journal of Clinical Psychiatry, v. 57z, p. 50-54, 1996.

BLACK, D. Compulsive buying disorder: definition, assessment, epidemiology and clinical management. CNS Drugs, v. 15, n. 1, p. 17-27, 2001

BLEULER, E. Textbook of psychiatry. New York: MacMillan, 1924.

BLOCH, P.; RIDGEWAY, N.; DAWSON, S. The shopping mall as consumer habitat. Journal of Retailing, v. 70, n. 1 p. 23-24, 1994.

BOEDECKER, K.; MORGAN, F; STOLTMAN, J. Excessive consumption: marketing and legal perspectives. American Business Law Journal, v. 36, n. 2, p. 301-325, Winter 1999.

CHRISTENSON, G.; FABER, R.; ZWANN, M.; RAYMOND, N.; SPECKER, S.; EKERN, M.; MACKENZIE, T.; CROSBY, R.; CROW, S.; ECKERT, E.; MUSSELL, M.; MITCHELL, J. Compulsive buying: descriptive characteristics and psychiatric comorbidity. Journal of Clinical Psychiatric, v. 55 , p. 5-11, 1994

D'ASTOUS, A. An inquire into the compulsive side of "normal" consumers. Journal of Consumer Policy, Netherlands: Kluwer Academic Publishers, v. 13, p. 15-31, 1990.

D'ASTOUS, A.; MALTAIS, J.; ROBERGE, C. Compulsive buying tendencies of adolescents consumers. Advances in Consumer Research, v. 17, p. 306312,1990

DESARBO, W.; EDWARDS, E. Typologies of compulsive buying behavior: a constrained clusterwise regression approach. Journal of Consumer Psychology, v. 5, n. 3, p. 231-262, 1996.

DHOLAKIA, U. M. Temptation and resistance: an integrated model of consumption impulse formation and enactment. Psychology \& Marketing, v. 17, n. 11, p. $955-968,2000$.

EDWARDS, E. Development of a new scale for measuring compulsive buying behavior. Financial Counseling and Planning, v. 4, p. 67-84, 1993.

ELLIOTT, R. Addictive consumption: function and fragmentations in postmodernity. Journal of Consumer Policy, v. 17, n. 2, p. 159-179, 1994.

ELLIOTT, R.; ECCLES, S.; GOURNAY, K. Revenge, existential choice and, addictive consumption. Psychology \& Marketing, v. 13, n. 8, p. 753-768, Dec. 1996.

FABER, R.; CHRISTENSON, G. In the mood to buy: differences in the mood states experienced by compulsive buyers and other consumers. Psychology \& Marketing, v. 13, n. 8, p. 803-819, Dec. 1996.

FABER, R.; CHRISTENSON, G.; ZWAAN, M.; MITCHELL, J. Two forms to compulsive consumption: comorbidity of compulsive buying and binge eating. Journal of Consumer Research, v. 22, n. 3, p. 296-304, Dec. 1995.

FABER. R.; O'GUINN, T. A clinical screener for compulsive buying. Journal of Consumer Research, v. 19, p. 459-469, Dec. 1992.

FABER. R.; O'GUINN, T. Compulsive consumption and credit abuse. Journal of Consumer Policy, v. 11, n. 1, p. 97-109, Mar. 1988.

FROST, R.; KIM, H.; MORRIS, C.; BLOSS, C.; MURRAY-CLOSE, M.; STEKETEE, G. Hoarding, compulsive buying and reasons for saving. Behaviour Research and Therapy, v. 36, p. 657-664, 1998.
GLATT, M.; COOK, C. Pathological spending as a form of psychological dependence. British Journal of Addiction, v. 82, p. 1257-1258, 1987.

HADDAD, C.; PATEL, U.; PIERRE, N. Diploma na mão, cheios de sonhos e endividados. Valor Econômico, Atlanta e Washington, 16 maio 2001. Disponível em: <www.valoreconomico.com.br>. Acesso em: 26 set. 2003.

HASSAY, D.; SMITH, M. Compulsive buying: an examination of the consumption motive. Psychology \& Marketing, v. 13, n. 8, p. 741-752, Dec. 1996

HIRSCHMAN, E.; STERN, B. Do consumers' genes influence their behavior? Findings on novelty seeking and compulsive consumption. Advances in Consumer Research, v. 28, p. 403-410, 2001

KWAK, H.; ZINKHAN, G.; CRASK, M. Diagnostic Screener for Compulsive Buying: applications to the USA and South Korea. The Journal of Consumer Affairs, v. 37, n. 1, p. 161-169, Summer 2003.

KRAEPELIN, E. Psychiatrie. 8. ed. Leipzig: Verlag Von Johann Ambrosius Barth, 1915.

LA BARBERA, P. The nouveaux riches: conspicuous consumption and the issue of self fulfillment. Research in Consumer Behaviour, v. 3, p. 179-210, 1988.

LEARNING the hard way: college students amass more credit card debit. Europe Intelligence Wire, p. 1-2, July 2003.

LEJOYEUX, M.; ADES, J.; TASSAIN, V.; SOLOMON, J. Phenomenology and psychopathology of uncontrolled buying. Journal of Psychiatric Association, v. 153, n. 12, Dec. 1996.

LYI, D.; LEE, S.; KWAK, H. Demographic trait and shopping attitude: impulsive buying and compulsive buying. Korean Journal of Advertising Research, v. 36, p. 127-137, Fall 1997a.

LYI, D.; LEE, S.; KWAK, H. Trait aspects of impulsive buying behavior. Korean Journal of Advertising Research, v. 34, p. 213-241, Spring 1997b.

MAGEE, A. Compulsive buying tendency as a predictor of attitudes and perceptions. Advances in Consumer Research, v. 21, p. 590-594, 1994.

MCELROY, S.; POPE, H.; HUDSON, J.; KECK, P.; SMITH, J.; WHITE, K. Kleptomania: a report of twenty cases. American Journal of Psychiatry, v. 148, p. 652-657, May 1991

MCELROY, S.; KECK, P.; POPE, H.; SMITH, J.; STRAKOWSKI, S. Compulsive buying: a report of 20 cases. Journal of Clinical Psychiatry, v. 55, p. 242-248, 1994a.

MCELROY, S.; PHILLIPS, K.; KECK, P. Obsessive compulsive spectrum disorder. Journal of Clinical Psychiatry, v. 55, p. 33-51, 1994b.

MILTENBERGER, R.; REDLIN, J.; CROSBY, R.; STICKNEY, M.; MITCHELL, J.; WONDERLICH, S.; FABER, R.; SMYTH, J. Direct and retrospective assessment of factors contributing to compulsive buying. Journal of Behavior Therapy and Experimental Psychiatry, v. 34, p. 1-9, 2003.

MOSCHIS, G.; CHURCHILL, G. Consumer socialization: a theoretical and empirical analysis. Journal of Marketing, p. 40-48, Summer 1978.

NATARAAJAN, R.; GOFF, B. Compulsive buying: toward a reconceptualization. Journal of Social Behavior and Personality, v. 6, p. 307328,1991 .

O'GUINN, T.; FABER, R. Compulsive buying: a phenomenological exploration. Journal of Consumer Research, v. 16, p. 147-157, Sept. 1989. 
PRATES, C. O consumidor compulsivo. Disponível em: <http:// www.klickeducacao.com.br>. Acesso em: 20 set. 2003.

REDDEN, J.; STEINER, C. Fanatical consumers: towards a framework for research. Journal of Consumer Marketing, v. 17, n. 4, p. 322-337, 2000

RINDFLEISCH, A.; BURROUGHS, J.; DENTON, F. Family structure, materialism, and compulsive consumption. Journal of Consumer Research, v. 23, p. 312-325, Mar. 1997.

ROBERTS, J.; MANOLIS, C.; TANNER JR, J. Family structure, materialism, and compulsive buying: a reinquiry and extension. Journal of Academy of Marketing Science, v. 31, n. 3, p. 300-311, Summer 2003

ROBERTS, J.; JONES, E. Money attitudes, credit card use, and compulsive buying among American college students. The Journal of Consumer Affairs, v. 35, n. 2, p. 213-241, Winter 2001.

ROBERTS, J.; SEPULVEDA, C. Money attitudes and compulsive buying: an exploratory investigation of the emerging consumer culture in Mexico. Journal of International Consumer Marketing, v. 11, n. 4, p. 53-74, 1999.

ROBERTS, J. Compulsive buying among college students: an investigation of its antecedents, consequences, and implications for public policy. Journal of Consumer Affairs, v. 32, n. 2, p. 295-308, Winter 1998.

ROOK, D.; FISHER, R. Normative influences on impulsive buying behavior. Journal of Consumer Research, v. 22, p. 305-313, Dec. 1995.

ROOK, D. The buying impulse. Journal of Consumer Research, v. 14, p. 189-199, 1987.

ROOK, D.; HOCH, S. Consuming impulses. Advances in Consumer Research, v. 12 , p. 36-40, 1984.
SCHERHORN, G.; REISCH, L.; RAAB, G. Addictive buying in West Germany: an empirical study. Journal of Consumer Policy, v. 13, p. 355387, Dec. 1990.

SCHLOSSER, S.; BLACK, D.; REPERTINGER, S; FREET, D. Compulsive buying: demography, phenomenology, and comorbidity in 46 subjects. General Hospital Psychiatry, v. 16, p. 205-212, 1994.

SHETH, J.; MITTAL, B.; NEWMAN, B. Comportamento do cliente. São Paulo: Atlas, 2001

SHOHAM, A.; BRENCIC, M. Compulsive buying behavior. Journal of Consumer Marketing, v. 20, n. 2, p. 127-138, 2003.

STERN, H. The significance of impulse buying today. Journal of Marketing, v. 26, p. 59-63, Apr. 1962.

ULLMAN, L.; KRASNER, L. A psychological approach to abnormal behavior. Englewoods Cliffs, N. J.: Prentice Hall, 1969.

VALENCE, G.; D’ASTOUS, A.; FORTIER, L. Compulsive buying: concept and measurement. Journal of Consumer Policy, v. 11, p. 419-433, 1988.

WARWICK, J.; MANSFIELD, P. Credit card consumers: college students' knowledge and attitude. Journal of Consumer Marketing, v. 17, n. 7, p. 617626,2000

WOODRUFFE-BUTTON, H.; ECCLES, S.; ELLIOTT, R. Towards a theory of shopping: a holistic framework. Journal of Consumer Behaviour, v. 1, n. 3, p. 256-266, Feb. 2002.

WOODRUFFE, H. Compensatory consumption: why women go shopping when they're fed up and other stories. Marketing Inteligence \& Planning, v. 15, n. 7, p. 325-334, 1997.

Artigo recebido em 14.10.2003. Aprovado em 28.05.2004.

\section{Tânia Modesto Veludo-de-Oliveira}

Professora de Marketing da UNIFECAP/SP. Mestre em Administração, com Especialização em Marketing, pela FEA/USP. Interesses de pesquisa em marketing de serviços, comportamento do consumidor e responsabilidade social.

E-mail: tveludo@usp.br

Endereço: Rua Joaquim Antunes, 553 apto. 102, São Paulo - SP, 05415-011.

\section{Ana Akemi Ikeda}

Professora Associada e Coordenadora da área de Marketing da FEA/USP. Interesses de pesquisa em marketing de serviços, pesquisa de marketing e comportamento do consumidor.

E-mail: anaikeda@usp.br

Endereço: Av. Prof. Luciano Gualberto, 908, Cid. Universitária, São Paulo - SP, 05508-900.

\section{Rubens da Costa Santos}

Professor de Marketing da FGV-EAESP. Interesses de pesquisa em valor percebido pelo cliente, responsabilidade social e comportamento do consumidor.

E-mail: rcsantos@fgvsp.br

Endereço: Av. 9 de julho, 2.029, $11^{\circ}$ andar, São Paulo - SP, 01313-902. 